\title{
Translation of Literary Texts: Categories for Text Analysis from Indian Traditions
}

\author{
Sushant Kumar Mishra
}

\begin{abstract}
:
The article deals with the basic problems of translation and surveys the basic theoretical issues in comprehension of source language text and communication in target language text. While briefly explaining the ideas of some eminent thinkers on translation, this article gives an idea how to use the categories of these thinkers for understanding text(s) for translation. These categories have been drawn from various western and Sanskrit theories on explaining the meaning contained in the language of a literary text. A general understanding of these categories, which have been briefly explained with examples, help us in training ourselves in the translation aspects while developing a proper theoretical understanding also of textual analysis for translation purposes. A work out on the text with these categories and with these theoretical understandings help us in training translators for literary translation.
\end{abstract}

There are two categories of problems in translation:

1. Problems of comprehension and understanding

2. Problems of communication or expression.

The denotation \& connotation of any Source Language (SL) text should be fully understood by the translator to be able to transfer the thought structure in Target Language (TL). Translation process can be divided into the following stages:

a) Perception of the SL text (superficial awareness of the original) 
b) Processing the result- e.g. identification of unfamiliar words, work with bilingual and monolingual explanatory dictionaries, grammatical structures, etc.)

c) Creation of TL material or construction of the semantic and connotative analog in the native language (Serghei G. Nikolayev 2000)

We can say that translation is an activity that aims at conveying the meaning or meanings of the SL text. "During recent years there has been a shift of emphasis from referential or dictionary meaning to contextual and pragmatic meaning. And the meaning of a given word or a set of words is best understood as the contribution that word or phrase can make to the meaning or function of the whole sentence or linguistic utterance or text where that word or phrase occurs." (Zaky 2000).

In translation, translation of idea is more important than lexical equivalence. A translator should translate the communicative function of the SL text, rather its signification. He, therefore, should look for a TL structure that has an equivalent communicative function, regardless of its formal resemblance to the original utterance and its structure.

J. C. Catford defines translation as, "the replacement of textual material in one language (SL) by equivalent textual material in another language (TL)" (Catford 1974: 20). He uses terms as Full Translation where the entire text is submitted to the translation process, i.e., every part of the Source Language text is replaced by Target Language text material. In Partial translation, some part or parts of the SL text are left untranslated or are incorporated in the TL text because of untranslatibility or lack of equivalent expression. In some cases it is done to retain the local colour in the translated text. In such cases footnotes are given to explain the meaning to the TL reader. In Free Translation the idea is translated ignoring the textual equivalence. 
Roman Jakobson, a Russian Formalist Thinker said, "The meaning of any linguistic sign in its translation into some further, alternative sign, especially a sign" in which it is more fully developed, "as Pierce, the deepest inquirer into the essence of signs, insistently stated" (Jakobson 1966: 232-33). There are three ways of doing it:

a. Intralingual translation or rewording is an interpretation of verbal signs by means of signs of the same language. e.g. Bachelor may be converted into a more explicit designation "unmarried man".

b. Interlingual or translation proper is an interpretation of verbal signs by means of some other language. On the level of interlingual translation, there is ordinarily no equivalence between code-units, while message may serve as adequate interpretations of foreign code-units or messages. e.g. The English word 'cheese' cannot be completely identified with its Hindi counterpart 'chena' or 'panir'.

c. Intersemiotic Translation or transmutation is an interpretation of verbal signs by means of signs of non verbal sign systems.

e.g.

usne sar hilaya

He nodded (his head) (English)

He shook his head
(Hindi)

(English)

The latter two translations are not equivalent expressions of the former in Hindi.

To find out equivalent expression is cardinal problem of translation studies. Translation from one language into another 
language substitutes message in one language not for separate code units but for entire message in some other language. Such as translation is 'reported speech': the translator records and transmits a message received from another source. Thus, "translation involves two equivalent messages in two different codes." (Jakobson 1966: 233).

A translator should have thorough knowledge of the TL and he should use his common sense when he comes across as ambiguous in the text. Certain freedom is to be taken with text to overcome these situations. The translated work should signify the same thing as the original text. Jakobson says that languages differ from each translation equivalent. For this he says, "whenever there is deficiency, terminology may be qualified and amplified by loan words or loan translation, neologisms or semantic shifts, and finally, by circumlocutions" (Jakobson, 1966:234). Jakobson emphasizes the role of translator as the person who decides how to carry out the translation by making appropriate choices to overcome the difficulties raised due to cultural or grammatical difference between Source Language Text (SLT) and Target Language Text (TLT).

Eugene A. Nida talks about Formal and Dynamic equivalence. By formal equivalence he means that the attention is focused on the message in both form and content. In formal equivalence closest equivalent of SL word or phrase is given in TL text. But formal equivalence might not be carried out always. In that dynamic equivalence is used. In Dynamic equivalence a translator translates the meaning of original in such a way that the TL text will have the same impact in TL audience/ readers as the original text had on the SL audience or readers. Nida emphasizes on dynamic equivalence for correct communication of information as in the SLT. Nida is much more interested in the meassage if the text i.e., in its semantic quality. For him it is essential that the message of the SL remains clear in the TL text. He explains four principles of translation:- 
1. Language consists of a systematically organized set of oralaural. This feature emphasizes on the speaker-listener system of the language. He also says that written form of any language is "a 'dependent symbolic system' and only imperfectly reflects the 'spoken-heard' form of language' (Nida, 1966:13). e.g.

a. Use of capital and small letters at the starting of a word can make a difference in the meaning of the word. e.g., God and god.

b. English language has both the capital and small letters but Indian languages do not have small and capital letters. Hence translation of God and god often becomes a problem to be resolved, often unsatisfactorily, in the context.

c. Some languages are written from right to left (English, Hindi, etc.), some are written from left to right (Urdu, Persian, etc) whereas some languages are written booth ways, i.e, first line from right to left and second line is written from left to right (some dialects of Greek Language).

2. Associations between symbols and referents are essentially arbitrary e.g., we use 'khat $\boldsymbol{k h a t}$ ' in place of 'Knock-knock'. Though both mean knocking on the door but the former one lacks softness and rhythm. Incase of 'phir-phir' or 'bak-bak' the visual/aural impact may be lost in translation.

3. The segmentation of experience by speech symbols is essentially arbitrary e.g., No two languages experience is similar because of cultural differences.

'Sar pït lena|'

He beat his head.

'Tulsi jaisa pavitra|' (correct in Hindi)

(not applicable in English language)
(Hindi) 
As pious as basal plant. (English)

In the translation of the above sentence from Hindi to English the essence is lost as the TL reader may not understand the association of 'pious' and 'basal plant' unless he is aware of its significance in culture associated with the Hindi language.

4. No two languages exhibit identical systems of organizing symbols into meaningful expressions. Nida says, "In all grammatical features, that is, order of words, types of dependencies, markers of such dependency relationships, and so on, each language exhibits a distinctive system" (Nida, 1966:13).

e.g., Truly I love you. (somebody truly in love)

Truly, truly I love you. (Emphasizing)

In some language in Philippines 'truly-truly' means 'Perhaps'. So in the latter sentence the meaning changes in literal translation.

'Panhuchate-panhuchate der ho gayi' - translation of this sentence in English poses problem as there is no equivalent grammatical structure with reduplication in English for this kind of sentence.

It means that there is $s$ problem of translatability. All types of translation involve:

a) Loss of information

b) Addition of information

c) Skewing of information

While translating a translator might face linguistic untranslatability (due to polysemy and oligosemy), cultural untranslatibility or Aesthetic untranslatibility. In such cases one has 
to keep in mind the Ethno linguistic Design of communication to understand the manner in which problems regarding translation occur. To construct an ethno linguistic design of communication we need simple components of the communication process (speaker, message \& receptor) and relate these to the entire communicative context.

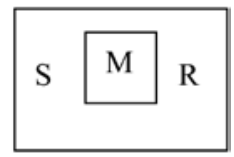

C

$\mathrm{S}=$ speaker as source $\&$ encoder

$\mathrm{M}=$ message as expressed in accordance with the particular structure (Inner square) of the language. The message can be anything from a single word to an entire utterance/text.

$\mathrm{R}=$ Receptor (including decoder and receiver)

And outer square designated by ' $\mathrm{C}$ ' represents cultural context as a whole, of which the message (as a part of language) is itself a part and model. It is impossible to deal with (the text of) any language as a linguistic signal without recognizing immediately its essential relationship to the cultural context as a whole.

Words and expressions like temple prostitutes (Devdasis), Jutha, 'Choti si kishori naach rahi mere aangan me' as a religious song are Hindu culture specific. Unless the TL reader is aware of the Hindu culture and society, it will be difficult for him to understand the message effectively. For same ' $M$ ', 'S' and 'R' differ in their cultural context as they are different individuals with different background. Each $\mathrm{R}$ interprets $\mathrm{M}$ on the basis of his language experience and understanding of each $\mathrm{R}$ is different. Therefore there is no absolute equivalence between $\mathrm{S}$ and $\mathrm{R}$ and $\mathrm{R} 1$ and $\mathrm{R} 2$ about the context of $\mathrm{M}$. 

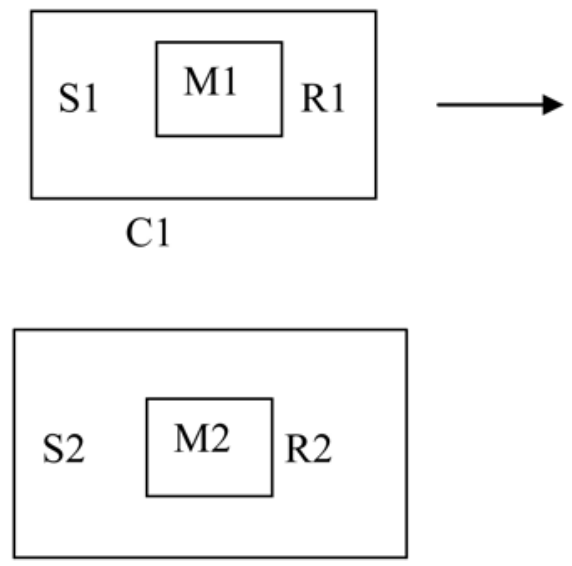

$\mathrm{C} 2$

C1\& C2: Cultural contexts of two different communities.

S1\& S2: Speakers as source and encoder. S2 here becomes receiver also as $\mathrm{R} 1$ in the context of translation. The translation received the message as R1 and then transmits the message as S2.

M1 \& M2: Message as expressed in accordance with the particular structure of language and culture.

R1 \& R2: Receptors (including decoder and receiver). In the above structures R1 who is receptor becomes speaker/sender as S2.

However when R1 is translated it becomes R2 in the translated text. The differences arise in M1 and M2 due to their relativity to \& relationship with the respective $\mathrm{C} 1$ and $\mathrm{C} 2$. Difference in factors between $\mathrm{C} 1$ and $\mathrm{C} 2$ will decide the communication between $\mathrm{S} 1$ and $\mathrm{R} 2$ and that will also decide the relationship between $\mathrm{M} 1$ and M2. R1 and S2 are both translators and S1 and R2 shares a very distant relationship. In translation $\mathrm{S} 1$ is being reported to R2 by the mediation of R1/S2. Therefore, we have two ethno linguistic communities involved which are different and change in information while translation is obvious. 
With the developments in the field of translation studies, transformational grammar, linguistics, semantics, information theory, anthropology, semiotics, psychology and discourse analysis etc., a new kind of approach has emerged. It is known as Sociosemiotic Approach. It is one of the best and most comprehensive one to study translation of fiction. Literary stylistics and linguistic approaches have many drawbacks when it comes to translation of the style, idea and nature of the SL text.

According to Yongfa $\mathrm{Hu}$, Translation of fiction is much more complicated than the translation of other genres, as it deals not only with bilingual but also bi-cultural and bi-social transference, including the entire complex of emotions, associations, and ideas, which intricately relate different nations' language to their lifestyles and traditions" (Yongfa $\mathrm{Hu}$, The Sociosemiotic Approach \& Translation of Fiction,2000).

Translation of fiction also involves the exchange of the social and language experience of individuals in the fictional world with readers in another culture. "Both the social factor and the authorial factor are emphasized in the process of fiction translation" (Yongfa, $\mathrm{Hu}$, The Sociosemiotic Approach \& Translation of Fiction,2000). Therefore, reproduction of style both of the text and author is considered the focal point in the translation of the fiction.

According to the Sociosemiotic Approach, "the text is a semantic unit with meaning and function. It is a product in the sense that it is an output, something that can be represented in systematic terms. It is also a process in the sense of ongoing semantic choices, a movement through the network of potential choices, each set of choices constituting the environment for a further set" (Yongfa, $\mathrm{Hu}$, The Sociosemiotic Approach \& Translation of Fiction,2000). The Sociosemiotic Approach says that there are three types of meaning of verbal signs:

a) Designative meaning (relationship between verbal signs and 
the referent)

b) Linguistic Meaning (relationship between signs )

c) Pragmatic Meaning (relationship between verbal signs and interpretants)

Sociosemiotic Approach helps in maintaining the style and essence of the SL text as well as in organizing the discourse. To sum up translation of fiction depends on various factors which includes aesthetic conventions, historical and cultural circumstances, among which the reproduction of styled and the meaning inherent in the SLT is of prime importance. The Sociosemiotic Approach takes into consideration all this.

Some of the concepts which help a translator to linguistically analyse the requirements of SL and TL effectively are as follows:

1. TRANSGRAMMING: Transgramming is defined as 'transferring grammar of one language into another'.

a.) In Telugu language, in kinship term in a Noun Phrase the possessive form will always be plural. So it will be always 'our mother' instead of 'my mother'.

b.) Yeh mera prem patra- Hindi (This sentences is correct)

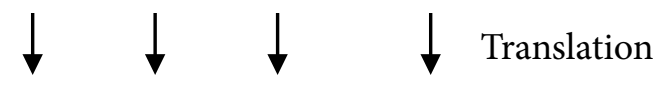

This my love letter- English (Unacceptable in English)

Word to word translation makes the latter sentence incorrect in usage as in English language a, an, the, my, you, this, that, those are paradigmatically related. So they cannot co-occur. 
2. TRANSMEANING: The recreation of the content of one language into content of another language is known as transmeaning. The Hindi word 'pakaranaa' has three possible translations - catch, hold, catch hold of. For a non Hindi speaker it will be difficult to understand and use the appropriate word as required by the context.

3. TRANSCREATION: It is more or less external version of transmeaning. In transcreation those words are chosen which fit the context properly. It also means making one's own theological choice while translation. e.g. In Telugu the word Brahmin means one who aspires for Brahmajnana and the word may have nothing to do with cast system denotation. So instead of Brahmin the word 'gyani' for 'pundit' is preferred to fit the translated context.

Transcreation is also used in case of cultural and historical problems posed by the SL text while transmeaning. e.g. In Kannada language and society the concept of Draupdi having five husbands is unacceptable. So the translator has to make his own theological choice to make the text socially acceptable. This was done in some translations of the original Mahabharata into the modern Kannada language.

4. FULL TRANSLATION: J.C. Catford defines this concept as, "In case of full translation the entire text is submitted to the translation process: that is, every part if the SL text is replaced by TL text material" (catford, 1974:21).

5. PARTIAL TRANSLATION: Some part or parts of the SL text are left untranslated. They are simply transferred to and incorporated in the TL text. In literary translation it is not uncommon for some SL lexical items to be treated in this way, either because they are regarded as 'untranslatable' or for the deliberate purpose of introducing 'local colour' into the TL text (Catford, 1974:21).

6. TOTAL TRANSLATION: Replacement of SL grammar and lexis by equivalent grammar and lexis with consequential 
replacement if SL phonology/ graphology by (Non-equivalent) TL phonology/graphology (Catford, 1974:22).

7. RESTRICTED TRANSLATION: "Replacement of SL textual material by equivalent TL textual material at only one level i.e. translation performed only at the phonological or at the graphological level, or at any one of the two levels of grammar and lexis" (Catford, 1974:22).

8. TRANSLITERATION: It is a complex process involving phonological translation with the addition of phonology-graphology correlation at both ends of the process, i.e. SL \& TL. In transliteration, SL graphological units are first replaced by corresponding SL phonological units: these SL phonological units are translated into equivalent TL phonological units: finally the TL phonological units are replaced by corresponding TL graphological units (Catford, 1974:66).

9.FREE TRANSLATION: "A free translation is always unbounded..." (Catford, 1974:25). Free translation may or may not have syntactic equivalence with the SL. The stress here is on the meaning to be conveyed and not on equivalence of SL text and TL material at lexical level.

\section{e.g. It's raining cats and dogs. (English) Bahut tez barish ho rahi hai| (Hindi)}

10. LITERAL TRANSLATION: Literal translation lies between free and word-for-word translation. It may start, as it were, from a word-for-word translation, but make changes in conformity with TL grammar (e.g. inserting additional words, changing structures etc.): this may make it a group by group or clause-to-clause translation (Catford, 1974:25).

11. BORROWING: When a word or phrase is taken from one language and used in another language, this process is known as 
borrowing. In case the borrowed word or phrase is difficult then it can be explained with the help of footnotes.

\section{e.g. tum free lectures me aa jaana| thanks sir!}

12. CALQUE: David Crystal defines Calque as a type of borrowing where the morphemic constituents of borrowed word or phrase are translated item by item into equivalent morphemes in the new language.

e.g. Weekend- saptaaha- anta (saptahaant)

Rain forest-varshaa-van

13. TRANSPOSITION: Transposition is defined as, "Interchanging the Grammatical categories without changing the meaning of the text". This can be used both in Interlingual and Intralingual translation.

e.g. a) He crossed the river.

(verb)

Vah nadi ke paar chala gaya|

(noun \& verb)

In the first sentence 'crossed' is a verb but in the translated sentence paar is a noun and 'chala gaya' is a verb. The grammatical categories have changed in the latter one.

b) He announced that he will come back.

$$
\text { Verb }
$$

He announced his return.

Noun 
In these two sentences 'come back' and 'return' refer to the same meaning. But the former one is a verb and the latter one is a noun.

14. MODULATION:- It is a variation in the message obtained by changing the point of view in the text. e.g. When we express a negative sentence of SLT by a positive sentence in TLT.

\section{Yah batana itna asan nahi hai.}

It is easy to say...(and negative comes later in the sentence) but not easy to understand.....

In this first sentence 'nahi' denotes negativity but the translated sentence has no negative complete negation. The word 'not' comes with 'easy' which is not a complete negation in the context.

15. EQUIVALENCE:- A relationship of equality of power between grammars. Grammars which generate the same set of sentences are said to be 'equivalent' or 'weakly equivalent'. Grammars which generate the same set of phrase - markers are 'strongly equivalent', i.e. they generate not only the same but assign the structural descriptions to each. Grammars which display differences in labeling or bracketing of structures, or which generate different sets of sentences, are said to be 'non- equivalent'. The term is also used in other syntactic and semantic contexts. E.g. 'Distributional equivalence' (between units with same distribution), 'semantic equivalence (i.e. synonymy)." (Crystal, 1974: 44). We understand 'equivalence' as 'creating similar expression and meaning' between the SL text and the TL text.

16. ADAPTATION: Modification of an idea in adjustment to the cultural surroundings is known as adaptation. Adaptation is done when the idea is absent in SL text, it is then presented differently in the TL material. E.g. The movie Rudali in which the text of Mahashweta Devi has been adapted from Bangla culture to Rajasthani culture and 
background.

17. ACTUALIZER: Whenever the fixed expressions are translated by their explanation in the context.

e.g. 'For Sale' - This car is for sale.

'To Let' - B/147 kiraaye par/ ke liye uplabdh hai

18. AMBIVALENCE: Uncertainty caused by inability to make a choice as words have different meanings. e.g.

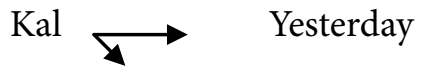

Tomorrow

19. AMPLIFICATION: Use of words more than the author has used to explain the SL text.

20. ANIMISM: Tendency to make a thing alive.

21. SYNATGMATIC ASSOCIATION: An effort by translator to keep the words of a sentence in TL text close to each other in the same way as they occur in the SLT. e.g.

\section{Maine usase kaha}

I talked to him./I told him...

12. DILUTION: Expression of an idea in many words. It is a kind of circumlocution where the text is diluted.e.g. Jutha - there is no equivalent of in English language for this word. So we have to explain it in text and that 'dilutes' the TLT.

13. CONCENTRATION: Expression of an idea in fewer words as compared to the original text. It is opposite of 'Dilution'.

14. OBLIQUENESS: When the idea of the SL text is indirectly 
expressed in TL text.

15. GENERALIZATION/ PARTICULARIZATION: When we translate a particular term (with concrete referent) by a general term (which is abstract). Generalization is opposite of particularization.

\section{e.g. a) usne bahut kuch padha hae}

He has read many books.

b) usne chabbiso kitaben padhi hain

There is no equivalent for the expression 'chabbisso' in the TL (English) but this sentence can also be translated by 'He has read many books'.

16. GRAMMATICALIZATION: When the referent lexical items in SLT are replaced by the grammatical terms in the TLT. It is a case of grammaticalization.

\section{e.g. vah bus ki chat per baith ker aaya}

He came sitting on the top of the bus.

17. EXPLICITNESS: When the meaning is fully and clearly expressed and can be understood clearly.

18. IMPLICITNESS: When the meaning is implied, rather than expressed in SLT. The listener/ reader has to deduce or infer the intended meaning from the source.

19. AMBIGUITIES (SEMANTIC \& SYNTATIC): In some cases there are more than one interpretation of a single sentence e.g. Old men and women. It can mean the both the men and women who are old or only men as old and not the woman.

20. If the ambiguity is in a single word it is called lexical ambiguity and in a sentence or clause it is called structural ambiguity.

21. NATIVES PREFERENCE: In some cases two sentences having same meaning are there. The sentence which is structured as closer 
to native's preference gets the priority.

22. MEMORY ASSOCIATION: When the similarity in two words and mention of one revives the memories of other.

23. IMAGE EXPRESSIONS: When any action or behaviour is described which has a certain meaning in the SL, the translator has to replace it by the equivalent imagery or just describe the meaning. e.g. sir khujalana| for thinking deeply.

24. ECONOMY: When the words used in TL text are less than the words in the SL text to express the same idea.

Now I am going to take the categories for analysis which are taken from the Indian literary and linguistic theories. To understand any text there are three levels at which the language has to be dealt with in order to understand the meaning intended by the author. At this level comes the problem of translation. There are three categories to understand the meaning of a text:

\section{ABHIDHA OR VACYA (EXPRESSED MEANING):}

Sujit Mukherjee defines it as "a term in poetics representing the function by which a word denotes its primary or conventional sense" (Mukherjee, 1999:1).

Mammata defines Abhidha in 2.7 of Kavyaprakash, "that which denotes the direct conventional meaning is the 'expressive' word." (Ganganath Jha, 1985)

\section{LAKSANA (INDICATION):}

According to Sujit Mukherjee "Laksana is a Sanskrit term in poetics which denotes a function by which a word expresses a sense other than its primary sense" (Mukherjee, 1999:200). 
Mammata defines laksana in karika 2.9 as "when the primary meaning is precluded (by incompatibility), another meaning, in affinity therewith, comes to be implied, either on basis of usage or for a special purpose, this process of imposed implication is called indication, laksana." (Ganganath Jha, 1985).

\section{VYANJANA (SUGGESTION):}

Vyanjana is defined by Sujit Mukherjee as 'term in poetics for that function by which a word suggests a sense which is other than its primary sense. (Mukherjee, 1999:426).

According to Mammata's concept, vyanjana is that function of word by which some meaning not established by usage is expressed or indicated. On the basis of Bhartarhari's Vakyapadiya, Mammata has given fifteen conditions that serve to bring about suggested meaning of a particular word:

a. SAMYOGA (CONNECTION): In the expression 'Hari with conch and discuss', the word 'Hari' means Vishnu. The word Hari has many meanings but this particular meaning is understood in connection with conch and discuss (Ganganath Jha, 1985:289).

b. VIPRAYOGA (DISJUNCTION): When the meaning is understood on the basis of disjoint connection. e.g. In the expression 'Hari without conch and discuss', the meaning of 'Hari' is understood as Vishnu because of disjunction of conch and discuss.

c. SAHACARYA (ASSOCIATION): In the expression Ramlaksamanau i.e. 'Ram and Laksaman', Ram is none other than the son of Dasaratha because of association with Laksamana.

d. VIRODHITA (ENMITY): In the expression 'the behaviour of these two combatants is like that of Rama and Arjuna', the meaning of 'Rama' is restricted to 'Parasurama' and that of 
'Arjuna' to 'Kritavirya'.

e. ARTHA (PURPOSE): In the expression 'worship sthanu for the purpose of removing the shackles of the world', the meaning if the word 'sthanu' is restricted to Siva.

f. PRAKARANA (CONTEXT): In the expression 'Deva knows everything', the meaning of the word 'Deva' is restricted to 'you'. This is done through context.

g. LINGA (PECULIARITY): In 'Makaradhvaja is angry', the meaning of the word 'Makaradhvaja' is restricted to the love-god as the quality of being angry is applicable only to God and not ocean.

\section{h. SABDASYA ANYASYA SANNIDHIH (PROXIMITY OF} ANOTHER WORD): In the expression 'devasya purarateh; the meaning of the word 'deva' is restricted to Siva because the proximity of the word 'purarati.

i. SAMARTHYA (CAPACITY): In 'Kokila bird is intoxicated by Madhu', the meaning of the word 'Madhu' is restricted to the 'spring' because only the 'spring' and not 'honey' or 'wine' has the capacity to intoxicate the bird.

j. AUCITI (COMPATIBILITY): In 'Patu vo dayitamukham' i.e. 'confrontation with the beloved's face', the meaning of the word 'patu' (which can mean 'drink' and 'protect' also) is restricted to 'confrontation' as only this meaning is compatible with the 'beloved's face'.

k. DESA (PLACE): In 'paramesvara shines here', the meaning of the word 'paramesvara' is restricted to the 'king' through the reference of the king's capital.

1. KALA (TIME): In 'citrabhanu is shining', the meaning of the 
word 'citrabhanu' is 'sun' if the statement is uttered during the day and 'fire' if uttered during the night.

m. VYAKTI (GENDER):- In 'Mitra shines', the word Mitra is used in the neuter gender and hence means 'friend' but if the word is used in masculine gender, it means 'sun'.

n. SVARA (ACCENT): In the expression 'Indrasatru' the meaning of the word depends on accent. It can mean 'whose killer is Indra' when the accent is on the first word 'Indra' and 'the killer of Indra' when the accent is on the second word 'satru'.

o. GESTURE: In the text it is indicated by adayah i.e. 'etc'. It serves to restrict the meaning in such passages as- 'during all these days the breast have reduced to this (marked by gestures) size, her eyes have shrunk to this (marked by gestures), and her condition has become like (marked by gestures).

A few categories of Mimamsa can also help us in analyzing a text for translation. some examples from Mimamsasutra of such categories are as follows (terms defined on the basis of Mimamsasutra, translated by M.L. Sandal):

a) SRUTI: It is a word or collection of words not depending on any other for its meaning. A word has a conventional sense attached to it: it is said to be its primary sense. Primary sense conveyed by a word without the help of any other is Sruti. It is directly heard and as soon as it is heard, a hearer understands its sense.

b) LINGA: It is the suggestive or the secondary sense of a word which can be inferred from another word or collection of words. As for instance "varhideva sadanandami" i.e. "I out thee, O grass for the seat of god." Though varhi is the generie term meaning grass, yet as the mantra is used for cutting the Kusa grass, it is used in the specific sense of Kusa grass. 
c) VAKYA: When the meaning of a word or a collection of words is clearly gathered from the sentence in which it is used, the principle which governs it is called Vakya. When the meaning of a word or collection of words is gathered from the whole sentence, it is called the principle of Vakya.

d) PRAKARANA: When a sentence is not clear and its meaning cannot be gathered without the context in which it occurs, the construction is governed by the principle of Prakarana.

e) STHANA: It is the location or order of words which help one in the interpretation. As for instance, there are mangoes, guavas, oranges, apples and pears; let John, Thomas, Mathew, Jardine and Lacy take them. According to the principle of sthana, the clauses mean that John is to take mangoes, Thomas guavas, Mathew oranges, Jardine apples and Lacy pears.

f) SAMAKHYA: It is a name or denomination. It is a compound word which should be broken up into its component parts and its meaning should be thus ascertained; as for instance, wine-cup (a cup from which one drinks wine) is distinguishable from the milk-cup. Tea-spoon, dessert spoon and table spoon fall under this definition.

These categories from the Indian traditions of studies on interpretation of text can be helpful in analyzing both SLT and TLT for making the translation more effective and powerful in its purpose.

\section{REFERENCES}

Basil Hatim and Munday Jeremy, 2004. Translation an Advance Resource Book, Routledge, New York.

Catford, J. C., 1974. A Linguistic Theory of Translation, Oxford University Press, London. 
Crystal David, 1985. A Dictionary of Linguistics * Phonetics (2nd Edition), Basil Blackwell Ltd., Oxford.

Hu, Yongfa, 2000. "The Sociosemiotic Approach and Translation of Fiction" in Translation Journal (online), www.accurapid.com

Jakobson, Roman, 1996. "On Linguistic Aspects of Translation" in On Translation, I.A. Richards (ed.), Oxford University Press, New York.

Jha, Ganganath, 1985. Kavyaprakash of Mammata with English Translation, Bhartiya Vidya Prakashan Oriental Publishers and Book Sellers, Delhi.

Mimamsasutra of Jaimini (translated by M.L. Sandal), 1980. Motilal Banarsidass, Delhi, First Edition 1923-25. Reprint

Mukherjee, Sujit, 1999. A Dictionary of Indian Literature (Vol - I), Orient Longman, Delhi.

Nida, Eugene A., 1996. "Principles of Translation as Exemplified by Bible Translating" in On Translation, I.A. Richards (ed.), Oxford University Press, New York.

Nikolayev, Serghei G., 2000. "Poor Results in Foreign $>$ Native Translation: Reasons and Ways of Avoidance" in Translation Journal, Volume 4, No. 4, October 2000. on URL http://www.bokorlang.com/ journal/14russian.htm, consulted at 12.30 on 5th December 2013 in Delhi.

Vinay J.P. \& J. Darbelnet, 1995. Comparative Stylistics of French and English: A Methodology for Translation, (translated by J.C. Sager \& M.J. Hamel), John Benjamins, Amsterdam/Philadelphia.

Yongfa, Hu, 2000. "The Sociosemiotic Approach \& Translatio of Fiction", on URL http://www.bokorlang.com/journal/14fiction.htm 2000 consulted at 14.30 on 5th December, 2013 in Delhi.

Zaky, Magdy M., 2000. "Translation \& Meaning" in Translation Journal (online), www.accurapid.com. 